\title{
A CONTRIBUIÇÃO DA EDUCAÇÃO SOMÁTICA NA FORMAÇÃO DO PERFORMER CONTEMPORÂNEO: O MÉTODO GDS
}

Evanize Siviero $^{1}$ (UFV-MG)

eva.siviero@gmail.com

Ana Macara ${ }^{2}$ (FMH/UL-PT)

amacara@fmh.utl.pt

\section{INTRODUÇÃO}

O corpo é um meio de comunicação extraordinário, que devemos conhecer e investigar. No campo das Artes Corporais, ao propormos uma análise mais profunda de seus aspectos, certos descompassos podem surgir sobre a maneira de o intérprete perceber e sentir o seu corpo em movimento, principalmente ao se deparar com um trabalho que lhe induza experienciar e refletir sobre um corpo mais sensível e integrado em aula e/ou em cena.

Pelos estudos, de autores como Fortin (1995), Bolsanello (2012) ou Denovaro (2012), entre outros, a Educação Somática vem influenciando o ensino da dança, a prática coreográfica, a melhora da performance de criadores e intérpretes, sendo também, aplicada como prevenção e tratamento de lesões. Desta forma este estudo visa trazer ao leitor quais as contribuições da educação somática, e em particular o método $\mathrm{GDS}^{3}$, para a formação do intérprete, criador e pesquisador em dança.

\footnotetext{
${ }^{1}$ Bacharel e Licenciada em Dança pela UNICAMP (1998), mestre em Ciências da Motricidade pela Universidade Estadual Paulista - Rio Claro (2004). Doutora pela Faculdade de Motricidade Humana - UL/PT (2014). Professora adjunta do curso de Dança da UFV/MG. Atua na área de Dança e Educação Somática; Didática para o ensino da Dança; Educação Especial e Dança-Teatro.

2 Professora Doutorada na FMH-Universidade de Lisboa. Investigadora do INET-MD com vários livros editados e publicados. Coordenadora do Mestrado em Performance Artística - Dança. Diretora Artística da Quinzena de Dança de Almada - Festival Internacional.

${ }^{3}$ A origem da sigla GDS esta associada ao nome da criadora do método - Godelieve Denys Struyf. Fisioterapeuta e osteopata belga que criou e desenvolveu o método nas décadas de 60 e 70, com o objetivo de obter uma leitura precisa do gesto, da postura e das formas do corpo por meio de uma avaliação não somente morfológica, mas também comportamental. (APGDS, 2015) 


\section{A EDUCAÇÃO SOMÁTICA: PRATICAS E TERAPIAS CORPORAIS}

A educação somática se apoia na singularidade do indivíduo e na experiência sensorial distintiva de cada pessoa como ponto de partida para desenvolver o autoconhecimento do corpo estático e em movimento. De acordo com Miller (2007, p. 22) a noção de corporeidade que a educação somática oferece está baseada nessa abordagem individualizada, no autoconhecimento e autodomínio. "Envolve o pensamento do corpo que é um estar presente em suas sensações, quando executa uma prática, sentindo e percebendo cada movimento, tornando cada um num espectador do seu próprio corpo.".

Dentre inúmeras formas de fazer com que tenhamos um olhar mais apurado e reflexivo sobre o corpo e suas mensagens, as práticas e as terapias corporais somáticas podem auxiliar neste caminho de reflexão e comunicação.

Como indaga Gil (1997), então que corpo é este em volta do qual se agitam estas terapias? De acordo com Martins (1999) as terapias somáticas constituem sistemas de tratamento não convencionais, inspirados em tradições orientais e ocidentais - espiritualistas, bioquímicas, psicológicas e educacionais. Essas terapias reivindicam cientificamente o seu valor a partir de parâmetros diferentes daqueles adotados na validação dos sistemas clássicos, dominantes do campo médico ocidental.

Embora derivada de métodos terapêuticos, a educação somática não pretende assumir funções de tratamento, mas possui objetivos de formação, fundada em princípios de saúde e das percepções mais sutis, que permitem ao indivíduo um melhor desenvolvimento de suas habilidades performáticas, criativas e mentais. Russo (1993) diz que o termo terapia permite a demarcação de fronteira relativamente ao conceito de educação somática, acreditando ser possível demarcar um território das práticas corporais, as quais se distinguem das terapias corporais por sua própria definição, já que, a educação somática não inclui a concepção de tratamento ou cura. 
Este território trilha caminhos que, embasados no corpo integrado, perpassam por trabalhos prático-teóricos que têm como foco a sensibilização, a expressão corporal e a prevenção. Buscam, assim, desenvolver um sistema para a prática do movimento com o intuito de resgatar o pensamento consciente e colocar o corpo em harmonia e em equilíbrio.

A maioria das práticas e terapias corporais trabalha com centros energéticos, com as articulações que o corpo produz entre suas estruturas (orgânicas, sensoriais e mentais) e com o mundo que o cerca, visando o despertar da propriocepção, que leva à consciência de posições e movimentos corporais.

Gaiarsa (1984, p.25) chama a atenção para “[...] o papel da(s) intenção (ões) que a cada momento é (são) configurada(s)." Essas intenções são normalmente ativadas por um conjunto de tensões musculares que nos impedem ou que nos liberam, dependendo de cada situação, de nossos estados emocionais, de nossa personalidade, do nosso imaginário; que recruta o que sentimos e o que vivemos, imprimindo assim o jeito e o modo de ser e fazer de cada um.

De acordo com Damásio (2000) as representações dos estados do corpo têm a função de fornecer informações precisas ao cérebro sobre o funcionamento geral do organismo, de modo que seja possível o completo gerenciamento de respostas e ajustes necessários à manutenção do seu equilíbrio e estabilidade.

Dentre estas representações, o sistema sensorial é o que desempenha esta função, sendo dividido em três fontes, no que à propriocepção diz respeito: a) a que monitora o meio interno e o das vísceras, denominada interoceptiva; b) a do tato que monitora qualquer alteração sofrida na pele, denominada exteroceptiva e c) a do sistema musculoesquelético, que comunica ao sistema nervoso central o estado dos músculos, ossos e articulações, a cinestésica que é de grande importância para as práticas somáticas e também para o nosso estudo, pois está mais intimamente ligada ao movimento corporal. 
Detalhes a respeito do tônus, ângulo de movimento e posicionamento de uma articulação, intensidade de estiramento de um músculo e outros estão entre as informações captadas pela propriocepção, que torna possível que nos movimentemos e saibamos o que acontece conosco, sem necessariamente ter que olhar para as partes do nosso corpo. (Domenici, 2010, p.31)

No entanto, nem todas as alterações ocorridas são percebidas conscientemente pelo indivíduo e um dos principais focos da educação somática é refinar esse processo. Usando as palavras de Lima: "Todas [as práticas somáticas] trabalham no sentido de desenvolver no indivíduo a consciência de seus próprios atos como instrumento de mudança" (Lima, 2010, p.61).

Esta relação é imprescindível nas práticas corporais somáticas, pois segundo Russo (1993) estas atividades nascem da vontade de auxiliar o homem a se harmonizar, liberando-se das tensões excessivas, recuperando o significado do gesto justo e a expressividade do movimento, quando estes se tornam vazios pelo cotidiano e fragmentados mascarando, assim, sua plenitude na sua mais pura expressão.

É certo afirmar que, através do seu corpo, cada indivíduo reage aos estímulos de diversas formas. As condutas assim assumidas revelam àquele que se dispõe a observar e fazer a sua leitura, certas predisposições posturais e de atitudes permitindo, que o caracterizam. Paralelamente, tomando consciência desta realidade podemos trabalhar através da percepção dos indicadores (elementos exteriores percebidos e elementos interiores vividos) e distinguir elementos potencialmente nocivos ao seu funcionamento, de forma a possibilitar a prevenção ou o diálogo via movimento corporal.

Neste sentido alguns teóricos como Paul Schilder, que revolucionou o conhecimento sobre a imagem corporal na primeira metade do século $X X$, ou Piret $e$ Béziers (1992) entre outros, legitimam esse pensamento em seus estudos. Schilder (1994), por exemplo, considera que os processos emocionais geram, fortificam e direcionam os processos de construção da imagem corporal, auxiliados pelas sensações e pelas percepções. 
Outro argumento de Schilder (1994) é que o movimento contribui para diminuir "cristalizações" que acometem o corpo, pois o modelo postural a cada gesto se modifica, fazendo com que a postura e o gesto não fiquem fixados a uma forma ou função. Para ele, "[...] a diminuição da rigidez da imagem corporal trará consigo uma determinada atitude psíquica. Assim, o movimento influencia a imagem corporal e nos leva de uma mudança da imagem corporal a uma mudança de atitude psíquica" (p.229).

Foi com este olhar que Godelieve Denys Struyf começou a pesquisar várias tipologias, a organização destas e seus vários segmentos e unidades.

Assim, Struyf $(1995,2009)$ estudou as cadeias musculares que suportam a nossa estrutura física e as relacionou a algumas atitudes psicocomportamentais, correspondendo a diferentes posturas do corpo. Todavia essas formas podem aparecer isoladamente, como uma estrutura dominante do corpo ou em variáveis combinações.

\section{O GDS}

Para uma organização de seu método Struyf $(1995,2009)$ denominou cada cadeia de acordo com a sua localização no corpo, assim apresentando seis cadeias morfocomportamentais.

O movimento provindo da articulação das seis cadeias musculares produz uma postura preferencial, na qual o gesto, por sua modalidade e sua repetição, pode determinar uma atividade mais importante em uma das cadeias. $\mathrm{O}$ excesso de tensão em uma cadeia muscular pode conduzir a forma incorreta (porque pouco funcional ou potencialmente suscetível de provocar lesões) e isto pode significar o sinal da desorganização. Quando uma cadeia muscular domina certa região, essa é marcada 
com um sinal que lhe é próprio diminuindo assim o potencial das outras cadeias e consequentemente afetando a atividade destas.

Enfim, para que isso não ocorra é importante destacar que todas essas cadeias morfocomportamentais, estudadas por Struyf $(1995,2009)$, do corpo humano devem funcionar juntas, sendo flexíveis e adaptadas a cada situação vivenciada pelo indivíduo. A detecção de problemas comportamentais relativos a cada uma destas cadeias, a sua conscientização e posterior trabalho no sentido de sua superação é à base de trabalho do método GDS.

\section{O MÉTODO GDS APLICADO ÀS ARTES DO CORPO}

Ao aplicarmos o método GDS ás artes corporais, especificamente neste estudo, na dança e percebemos que o GDS é possível de ser melhor compreendido, por meio da experimentação, através de exercícios de conscientização e alongamentos das diferentes cadeias musculares, além de sua aplicação em alguns jogos dramáticos, aperfeiçoando o processo de comunicação. Em outras palavras o movimento humano compreende a possibilidade de diálogo com o mundo, estabelecendo novos significados em cada instante na sua relação de interdependência entre o espaço biológico, social e cultural, refletindo-se em atitudes e posturas, como as estudadas por Struyf.

Enfim, conhecer a estrutura óssea, o seu eixo de equilíbrio vertical e relacional, a musculatura que sustenta esta estrutura, que promove movimento corporal, perceber o quanto e como empregamos a nossa força para as ações básicas ou mais elaboradas, são atributos básicos para a educação somática de qualquer pessoa, da mesma maneira que a educação básica comportamental existe em qualquer grupo social. Com base no entendimento de que o movimento envolve conhecimento do corpo adquirido pela experiência, o método GDS foi proposto como uma vivência com 
o objetivo de trabalhar uma organização corpórea global e equilibrada, sendo por isso mais funcional. Acreditamos que existe uma sinergia entre a dança e este método que pode, não apenas reduzir muito os efeitos dos desgastes que são inevitáveis com o tempo, como contribuir para um refinamento das qualidades performativas.

Enfim, diferentes métodos de educação somática utilizam estratégias pedagógicas que visam levar o indivíduo a tomar consciência da relação entre cada movimento, e a totalidade de seu corpo e o método GDS não foge a essa regra.

Portanto, a nossa intenção ao aplicar este método em aulas de dança não é a de que o instrutor execute para ser imitado, mas que a própria experiência e percepção do aluno sejam o veículo da mudança. Essa fase de tomada de consciência faz parte de um processo de aprendizagem, que permite que o intérprete retome movimentos primários e posturas naturais que se podem perder ao longo de sua formação por conta de uma automatização técnica e fruto das tensões diárias. Essa será a via para que novas maneiras de estar sejam reaprendidas e desenvolvidas ou aprimoradas não somente para a sua formação profissional, mas para também para a sua vida e longevidade na carreira.

\section{METODOLOGIA}

Como dissemos, este texto tem por objetivo apresentar algumas contribuições da aplicação do método GDS na formação de futuros performers. Esta pesquisa faz parte de uma investigação maior, de doutoramento, realizada na Faculdade de Motricidade Humana da Universidade de Lisboa - FMH/UL em Portugal sobre o método GDS, dança, movimento expressivo e performance.

Como metodologia baseamos este estudo na pesquisa-ação que, segundo Pimenta (2005), pode ser realizada no contexto de sala de aula por um trabalho de reflexão sobre a prática, além de promover a aproximação dos participantes com o 
pesquisador, estimulando-os a relatarem, com maior consciência, suas práticas a partir do trabalho com a pesquisa.

Assim sendo, participaram deste estudo 32 alunos do curso de Dança da Universidade Federal de Viçosa- MG, sendo 29 do sexo feminino e 3 do sexo masculino. Todos assinaram o termo de consentimento livre e esclarecido e também tiveram os seus nomes modificados para resguardar as suas identidades, cumprindo as regras éticas para a pesquisa em ciências sociais e humanas.

Para o desenvolvimento da pesquisa fizemos duas aplicações do Método GDS em aulas de dança. A primeira aplicação, à qual demos o nome de Grupo 1 - G1, participaram 10 alunos (oito do sexo feminino e dois do sexo masculino). O período de aulas teve duração de um mês, sendo um trabalho intensivo com sessões de 2 horas e 30minutos, cinco dias na semana, totalizando 44horas. A segunda aplicação, denominada de Grupo 2 - G2, com 22 inscritos (21 do sexo feminino e 1 do sexo masculino) com duração de 3 meses, com aulas de 2 horas e 30 minutos, uma vez na semana, também teve uma carga horária de 44horas.

A ideia de se trabalhar com dois grupos ( $G 1$ e $G 2$ ) se deu no intuito de verificar se haveria influência dos fatores tempo e intensidade ao trabalharmos com o método GDS em aulas de dança, lembrando que estes participantes não tiveram qualquer contato com o método antes das aplicações deste estudo.

Para coletar os dados das aulas optamos por utilizar o diário de bordo, a entrevista focal e gravações das aulas. O tratamento dos dados foi realizado por meio de análise quantiqualitativa. 


\section{CONTRIBUIÇÃO DO MÉTODO GDS NA FORMAÇÃO PERFORMER COMTEMPORÂNEO}

Quanto à contribuição do método GDS para a formação do performer em que visa um trabalho voltado para o corpo, para o movimento e para a dança em formação acadêmica e/ou profissional 50\% dos alunos do G1 e 63\% dos alunos do G2 afirmaram nas entrevistas que o estudo das cadeias morfocomportamentais reforçou o olhar "clínico" para com os seus corpos e para com o corpo do outro, ajudando na consciência corporal e do movimento, obtendo-se assim uma melhor qualidade estética e performativa: Como afirma João, do G1, "Esta sessão contribuiu para minha formação como bailarino a partir da hipótese de que utilizando as posturas do método GDS e transitando por elas, ganho maior qualidade estética na movimentação."; Alma, do G1, valoriza “... a preocupação estética e sensorial a respeito das transições e ligações exigidas pela dança."; "Conhecer melhor o meu corpo, saber controlá-lo e não ter uma postura fixada amplia a possibilidade de eu 'crescer' como bailarina", diz Luiza, do G1; Também Denise, do G1, aponta que este método: "Contribui, como na questão para eu estar preparada para fazer um bom espetáculo na questão de mudanças de posturas durante uma apresentação"; "Prestar mais atenção no que minhas atitudes corporais, posturais transmitem é de extrema importância para qualquer dançarina, pois ela precisa saber como se posicionar para transmitir a sensação que quer provocar". (Júnia, do G2); "Contribui para meu desenvolvimento como bailarina, percebendo as movimentações do meu corpo, e também me faz perceber melhor o corpo do outro." (Dara, do G1).

O método GDS aplicado à dança confirma o que Souza (2012) argumenta sobre a educação somática, em que na prática se constrói um modelo de ensino-aprendizado que educa os alunos a aprender. Essa aprendizagem, que passa pela experiência das ações aplicadas à dança baseadas nos princípios do método GDS, trouxe mudanças significativas para a formação do bailarino, também no sentido de compreender melhor os processos de aprendizado de modo geral, o que o leva a reconhecer que, apesar de comumente construídos no coletivo, esses processos são individuais, 
referenciados pela experimentação de cada um e pela capacidade de se auto perceber e de gerar autonomia. É, como descreve Souza (2012, p.70):

[...] a autonomia aqui tratada está diretamente ligada à capacidade de autoorganização, (re) formulação constante de si a partir das experiências vividas. Para cada pessoa, o processo de assentamento e integração das novas informações se dá de um modo distinto e num tempo particular e, pelo que foi apreendido dos alunos, a experiência com educação somática nas aulas de dança ensinou a eles como se colocar ativamente nesse processo, levando-os a assumir uma postura de corresponsabilidade com relação ao aprendizado durante as aulas, tanto quanto com relação às suas atividades profissionais.

Também foi destacado por $50 \%$ dos alunos dos dois grupos que o processo de lapidação pelo método resultou não apenas em um mecanismo propulsor da qualidade performática, mas também em um processo sem muitos desgastes emocionais e físicos prejudiciais, funcionando mesmo como prevenção de lesões: "Como bailarina, acredito que o pensar mais consciente trará mais mobilidade ao meu corpo, menos lesões futuramente e adaptabilidade a cada postura, facilitando o estudo das limitações do próprio corpo." (Lúcia, do G2);

As vantagens do trabalho desenvolvido são também apontadas para o desempenho do bailarino no processo de criação coreográfica:

Contribui para que eu tenha conhecimento de estímulos para composição coreográfica e uma melhor didática dentro da sala de aula, conhecendo as posturas dos alunos, posso trabalhá-las para um melhor desempenho dos alunos. (Pluma, do G1);

O conhecimento dessas posturas contribui para que possamos nos adaptar cada vez mais a diferentes movimentos. Ajuda-nos também na composição coreográfica (Laís, do G2).

Também a criação do personagem pode ser facilitada através deste método:

[...] por que podemos levar à nossa mente as diferentes personalidades $e$ posturas e colocar isso na nossa célula; como na construção de personagem. Para mim que venho do teatro, é um ganho incalculável. (Laís, do G2) 
Assim, podemos dizer que a diversidade de ações propostas neste estudo abordou aspectos biomecânicos, conhecimentos anatômico-funcionais, qualidades e princípios de movimento, dinâmicas, acionamentos e outros que, através da experiência sensorial, do jogo e do refinamento perceptivo, favoreceram o aprofundamento da compreensão das nuances e sutilezas, características do método GDS aplicado na dança.

Cerca de $40 \%$ dos alunos do G1 e 50\% do G2 relataram em seu diário de bordo que o método GDS contribuiu para a sua formação em dança, na criação coreográfica, no desenvolvimento da criatividade e no movimento expressivo: "A contribuição para a minha formação é a de poder e saber transitar entre as posturas conscientemente $e$ organicamente. E também utilizar desse conhecimento para a prática da dança, tanto como intérprete, quanto como criadora. (Ariene, do G1); O trabalho desenvolvido "Trouxe mais opções de criação de movimentos. Cada aula me conscientiza mais sobre as posturas e como pode me ajudar a aperfeiçoar meus movimentos." (Telma, do G2); "A descoberta de novas maneiras de se coreografar em tão pouco tempo, processos criativos que saem coisas inesperadas, pois são movimentos que geralmente não tenho costume de fazer." (Cláudia, do G2);

Na minha formação como bailarina, eu preciso muito mais de criatividade e prática em exercícios de criação a partir de estímulos ou em mostrar meu trabalho para alguém me avaliar e dar uma nota, por exemplo. Então, com certeza, essas atividades me trarão pontos de partida ou chegada para a construção de algum trabalho. (Lurdes, do G2)

Encorajar os alunos a encontrar o seu modo de realização de uma determinada sequência de movimentos, ou a confiar nas suas próprias sensações, buscando estratégias individuais de aprendizado e performance, faz com que, na verdade, haja o exercício de autonomia, dizendo-Ihes que é possível e desejável que tracem caminhos próprios e estejam acolhendo a pluralidade de escolhas e respostas apresentadas, rompendo com a lógica de apenas uma resposta correta e esperada, comum no modelo tradicional de ensino da dança. 
Por fim, $50 \%$ dos alunos do $\mathrm{G} 1$ e $70 \%$ do $\mathrm{G} 2$ relataram que o método contribuiu para que eles, como profissionais da dança, possam em suas aulas conhecer melhor seus alunos e a si mesmos, não só pelo corpo, mas também pelo comportamento, para conseguir trabalhar suas dificuldades e sua expressividade na dança: "O trabalho e a escolha do método têm muito a contribuir para a dança e para a formação de professores de dança e... de um professor capaz de compreender os problemas $e$ dificuldades dos alunos através de suas expressões." (Inaiá, do G1); E como diz Dara, do G1, este trabalho permite "[...] conseguir identificar no outro, diferentes posturas $e$ melhores maneiras de se realizar um determinado movimento, fator útil quando eu ministrar aulas de dança.".

\begin{abstract}
Está sendo uma experiência maravilhosa na minha vida profissional e pessoal, cada dia penso em me dedicar cada vez mais para aprimorar e melhorar meus movimentos e minhas ideias. Sinto em cada sessão que não só eu, mas todas as pessoas estão em constante mudança e temos certeza que o curso foi 100\% responsável por isso. Percebi os esforços desnecessários que faço para realizar algo simples e fácil. (Ariene, do G1)
\end{abstract}

Os alunos também puderam exercitar a memorização e a adaptação de seus corpos a movimentações diferentes que não estavam acostumados a realizar. A utilização do GDS aplicado à lapidação das movimentações permitiu que experimentassem um novo método de trabalho, onde diferentes corpos conseguem se adaptar ao movimento e a harmonização acontece com mais facilidade. Acreditamos que isto aconteceu por causa da conscientização das posturas permitindo um trabalho dinâmico entre os bailarinos nos processos criativos. Como depõem as alunas do G2:

[...] Adquiro com essa nova consciência corporal uma imagem mais real da organização corporal que possuo, isso auxilia minha movimentação e a forma como me organizo no espaço, sozinha ou em contato com outros corpos. (Cássia, do G2)

[...] cada sessão o conhecimento que adquiri foi realmente fundamental para minha formação e minha carreira de bailarina, e irá me auxiliar imensamente quando for ministrar alguma aula, ou participar de algum espetáculo e também se for montar uma coreografia. Eu recomendo o curso para todas as pessoas de dentro ou fora da área da dança, pois é de uma conscientização corporal realmente sem limites, e quanto mais nos 
aprofundarmos nisso, quanto mais praticarmos essa nova aprendizagem, melhor será nossa relação com nosso corpo. (Lourdes, do G2)

Portanto, os elementos destacados pelos alunos quanto à influência do método GDS sobre as suas formações em dança reforça a compreensão da sua contribuição para um desenvolvimento consciente de seus corpos, auxiliando no movimento expressivo e performático de cada um, ampliando os caminhos do intérprete para uma melhor performance em cena ou em aula e para o professor como um elemento didático-pedagógico para o ensino da dança. Nesse sentido, concordamos com a educadora norte-americana Jill Green: “[...] a tendência de a educação somática tornar-se uma 'nova área de estudo dentro da dança' ou uma 'subdisciplina em dança' é muito positiva no sentido de trazer o corpo de volta para a dança e para o currículo de formação do dançarino". (Green, 2002, p. 113). E através deste estudo podemos perceber como o método GDS, com toda a sua especificidade, provindo da área da terapia, é visto pelos praticantes como extremamente útil para uma melhor percepção do corpo, uma melhoria do desempenho em termos performativos e criativos, e para o conhecimento de futuros alunos.

\section{CONSIDERAÇÕES FINAIS}

Pensando em um método didático-pedagógico que oferecesse elementos substanciais para contribuir com o desenvolvimento das qualidades expressivas do performer e que estimulasse ao mesmo tempo suas potencialidades criativas e de autonomia, escolhemos para essa finalidade o método GDS para poder realizar uma leitura da realidade somática do sujeito, promovendo informações sobre os estados corporais e comportamentais resultantes da relação e experiência do indivíduo com o mundo e na Arte, com a finalidade de este método ser mais um agente propulsor de um ensino com qualidade.

Neste estudo, a vivência do método aplicado à dança foi articulada com o processo corporal dos alunos, que envolveu uma trama que integrou movimento, sensação, percepção, visão, imagem de si e da representação do próprio corpo, na 
intenção de colocar os alunos como sujeitos das ações, em que tivessem a oportunidade de lançar questões, de se envolver e compreender suas posturas e seus comportamentos, provocando reflexões e mudanças que pudessem influenciar o desempenho e a atuação do bailarino em sala de aula e em cena, contribuindo assim para a sua formação em dança.

Concluímos que não só os participantes no estudo desenvolveram capacidades performativas essenciais, como se perceberam da importância que este método que poderá vir a ter também como um importante instrumento na sua futura atuação como professores e para outras linguagens da Arte.

\section{REFERÊNCIAS BIBLIOGRÁFICAS}

A.P.G.D.S. Associação de Praticantes do Método G.D.S. Disponível em: http://apgds.com.br/metodo. Acesso em: 20 de maio de 2015.

BOLSANELLO, Débora Pereira. A Educação Somática e o contemporâneo profissional da dança. Disponível em: http://www.argeu.ceart.udesc.br. Acesso em: 14 de agosto de 2013, 2012, p.1-17.

DAMÁSIO, Antônio. O mistério da consciência. São Paulo: Companhia das Letras, 2000. DENOVARO, Daniel Becker. A Educação Somática na formação do ator: A contribuição do método Pilates. Repertório, Salvador, no. 18, v. 1, 2012, p. 94-100.

DOMENICI, Eloisa. O Encontro entre a Dança e Educação Somática como uma interface de questionamento epistemológico sobre as teorias do corpo. Pro-Posições, no. 21, v.2, Campinas, maio/ago, 2010. p. 69-85. 
FORTIN, Sylvie. Toward a new generation: somatic dance education in academia, Impulse: The International Journal of Dance Science, Medicine and Education, no. 3, v.4, 1995, p 253-262.

GAIARSA, José Ângelo. Couraça Muscular do Caráter (Wilhelm Reich). São Paulo: Agora, 1984.

GIL, José. Metamorfoses do Corpo. Lisboa: Relógio D’agua, 1997.

GREEN, Jill. Somatic Knowledge: the body as content and methodology in dance. Journal of Dance Education. New Jersey, no. 2, v.4, 2002, p.114-118.

LIMA, José Antônio de Oliveira. Educação Somática: Diálogos entre educação, saúde e arte no contexto da proposta da Reorganização Postural Dinâmica. Campinas: Programa de Pós-Graduação da Faculdade de Educação/Universidade Estadual de Campinas - UNICAMP, 2010. Tese (Doutorado em Educação).

MARTINS, Pedro Henrique. As Terapias Alternativas e a Libertação dos Corpos. In: Carozzi, Maria Julia (Org.). A Nova Era no Mercosul. Petrópolis: Vozes, 1999.p.80-105. MILLER, Jussara Correa. A Escuta do Corpo: Sistematização da Técnica de Klauss Vianna. São Paulo: Summus, 2007.

PIMENTA, Selma Garrido. Pesquisa-ação crítico-colaborativa: construindo seu significado a partir de experiências com a formação docente. Educação e Pesquisa. São Paulo, 31(3), set./dez, 521-539, 2005.

PIRET, Suzanne e BÉZIERS, Marie-Madeleine. A coordenação motora: Aspecto mecânico da organização psicomotora do homem. São Paulo: Summus editorial, 1992. 
RUSSO, Jane. O corpo contra a palavra: As terapias corporais no campo psicológico dos anos 80. Rio de Janeiro: Ed. UFRJ, 1993.

SCHILDER, Paul. A Imagem do Corpo: As energias construtivas da psique. São Paulo: Martins Fontes, 1994.

SOUZA, Beatriz Adeodato Alves de. Corpo em dança: 0 papel da educação somática na formação de dançarinos e professores. Salvador - BA: Programa de Pós-Graduação em Dança/Universidade Federal da Bahia, 2012. Dissertação (Mestrado em Dança).

STRUYF, Godelieve Denys. Cadeias Musculares e Articulares: 0 método G.D.S. São Paulo: Summus, 1995.

Les chaînes musculaires et articulaires. 6aㅡ ed. Reprise par I'ICTGDS. Bruxelles: Prodim, Vigot-Maloine, 2009. 